\title{
Flexural strength of a pressable lithium disilicate ceramic: influence of surface treatments
}

\author{
Tabata do Prado Sato, Caroline Cotes*, Lígia Tiaki Yamamoto, Natalia Rivoli Rossi, Vanessa da Cruz Macedo \\ and Estevão Tomomitsu Kimpara
}

\author{
* Correspondence: \\ caroline_cotes@yahoo.com.br \\ Institute of Science and Technology, \\ UNESP - Univ Estadual Paulista, \\ José Longo, 777, São Dimas, São \\ José dos Campos, Brazil
}

\begin{abstract}
The aim of this paper was to evaluate the influence of different surface treatments on the flexural strength of a pressable lithium disilicate ceramic. Sixteen bars $(16 \times 2 \times 4 \mathrm{~mm})$ were made, divided into subgroups $(n=10)$, and the following surface treatments were done: $\mathrm{C}$ - no treatment; $\mathrm{H}$ - etching with $5 \%$ hydrofluoric acid; $\mathrm{HC}$ - etching with $5 \%$ hydrofluoric acid, silanization, and cementation; $\mathrm{N}$ - etching with $5 \%$ hydrofluoric acid, neutralization with supersaturated solution of sodium bicarbonate, silanization, and cementation; $\mathrm{U}$ - etching with 5\% hydrofluoric acid, ultrasonic cleaning in distillated water, silanization, and cementation; NU - etching with $5 \%$ hydrofluoric acid, neutralization with supersaturated solution of sodium bicarbonate, ultrasonic cleaning in distillated water, silanization and cementation. The three points flexural strength was performed $24 \mathrm{~h}$ after cementation and the data were analyzed using one-way ANOVA and Tukey's tests ( $p$-value $=0.05$ ). The results showed that the surface treatment had a significant effect $(p$-value $<0,05)$ on the flexural strength of the studied ceramic. The $\mathrm{N}$ and $\mathrm{NU}$ groups showed lower flexural strength than other groups. Thus, it was concluded that neutralization with supersaturated solution of sodium bicarbonate, followed or not by ultrasonic cleaning results in lower mechanical strength of a pressable lithium disilicate ceramic. The etching with 5\% hydrofluoric acid did not reduce the flexural strength of this ceramic type.
\end{abstract}

Keywords: Dental ceramic; Flexural strength; Surface treatment; Hydrofluoric acid

\section{Background}

The dental ceramic are widely used and studied in dentistry. Processing methods of these materials are varied and can be categorized by different laboratory techniques. which results in different distribution of flaws, translucency degrees, and marginal and internal fit [1]. The pressable method technique can be used for IPS e.max Press, which is a lithium disilicate glass ceramic with the improvement of mechanical and optical properties and adequate fit [2].

For luting lithium disilicate ceramic, the surface treatment is etching with hydrofluoric acid (HF), which generates microporosities because of the glass phase and silica oxide dissolution. This treatment produces topographical changes, which increases the micromechanical retention and chemical bond with the silane and resin cements, reflecting on the values of bond strength between the ceramic and cement [3]. The lithium disilicate ceramic must be etching with HF, with an application of silane prior 
to cementation, but the etching generates acid precipitates that may affect the bond between ceramic and cement [4]. Therefore, it is necessary to use some protocols such as post-etching ultrasonic cleaning bath or neutralization [4-6].

The neutralization after etching does not recommended, but if the clinician prefer to do it, it is necessary to do ultrasonic cleaning bath after the neutralization [4]. The ultrasonic cleaning bath with distilled water appears to increase the bond strength between the resin cement and ceramics, because of the precipitates removal [7]. But there is not any study in literature that evaluate the post-etching protocols influence in ceramic mechanical properties. So, the aim of this study was to evaluate the influence of some surface treatments in the flexural strength of a lithium disilicate ceramic.

\section{Methods}

The ceramic bars (IPS e.max Press, Ivoclar Vivadent, Schaan, Liechtenstein) were prepared using a metallic matrix with dimensions of $2.2 \mathrm{~mm} \times 16.2 \mathrm{~mm} \times 4.2 \mathrm{~mm}$ [8]. To produce the ceramic bars this matrix was placed on a glass plate, and thin wax layers were poured, in order to prevent distortion, until the complete filling with a slight excess that was removed with a sharp instrument. The wax bars $(\mathrm{N}=60)$ were sprued, and attached to a muffle base. Then, they were invested with phosphate-based material (IPS PressVES, Ivoclar Vivadent, Schaan, Liechtenstein), following the manufacturer's recommendation. The heating and injection protocols were also indicated by the manufacturer using oven model P5000 (Ivoclar Vivadent, Schaan, Liechtenstein). After the cooling process at room temperature, the specimens was polishing with 800 and 1200 -grit diamond papers. Before the surface treatment, they were cleaned in ultrasonic bath for $4 \mathrm{~min}$ in distillated water.

Then, the bars were aleatory separated in six groups $(\mathrm{n}=10)($ Table 1$)$.

The HF (Formula e Ação, São Paulo, Brazil) etching was perfomed for $20 \mathrm{~s}$. Then, the bars were washed with air-water spray for $40 \mathrm{~s}$ and dried for $30 \mathrm{~s}$.

In the groups $\mathrm{N}$ and $\mathrm{NU}$, the bars were submerged in supersaturated solution of sodium bicarbonate (SB) (Portuense, Juiz de Fora, Brazil) for $40 \mathrm{~s}$ and washed for $5 \mathrm{~s}$.

In the groups $\mathrm{U}$ and $\mathrm{NU}$, the ultrasonic cleaning bath was performed in a ultrasound (Cristófoli Equipamentos, Campo Mourão, Brazil) with distillated water for $4 \mathrm{~min}$.

In groups submitted to cementation, silane (Monobond S, Ivoclar Vivadent, Schaan, Liechtenstein) was applied and, after $60 \mathrm{~s}$, an air spray was applied for $5 \mathrm{~s}$. Then, equal parts of base and catalyzer pastes of the resin cement (Variolink II, Ivoclar Vivadent, Schaan, Liechestein) were mixed for 10 seconds and applied on the bars. They were

Table 1 Surface treatment groups

\begin{tabular}{ll}
\hline Group & Surface treatment \\
\hline $\mathrm{C}$ & No treatment \\
\hline $\mathrm{H}$ & Etching with $5 \% \mathrm{HF}$ \\
\hline $\mathrm{HC}$ & Etching with $5 \% \mathrm{HF}$, silanization, and cementation \\
\hline $\mathrm{N}$ & Etching with $5 \% \mathrm{HF}$, neutralization with SB, silanization, and cementation \\
\hline $\mathrm{NU}$ & Etching with $5 \% \mathrm{HF}$, ultrasonic cleaning bath in distillated water, silanization, and cementation \\
\hline
\end{tabular}

Legend: Surface treatments used in this study $(n=10)$. 
kept under constant load of 750 g. The light curing unit (RadiiCal Polimerize, SDI, Victoria, Australia) with light intensity of $1200 \mathrm{~mW} / \mathrm{cm}^{2}$ light cured each face for 2 seconds to facilitate the removal of excess of cement. Forty seconds of light activation was performed on each side of the bars. After the cementation, the samples were stored in distilled water at $37^{\circ} \mathrm{C}$ for $24 \mathrm{~h}$.

In the mechanical testing, the bars were placed in a three-point bending test, in a metallic device, supported on two cylinders (2 mm diameter) with a distance of $16 \mathrm{~mm}$ between centers. Only the extremities of the samples were used for support, so the central area remained free to receive the load. The load was applied to the cementation opposite surface, by cylindrical rod ( $2 \mathrm{~mm}$ diameter) that was attached to universal testing machine (EMIC DL 1000, São José dos Pinhais, Brazil). The compressive load ( $\mathrm{v}=1 \mathrm{~mm} / \mathrm{min}$, load cell of $50 \mathrm{kgf}$ ) was applied until catastrophic failure [9,10]. All mechanical testing occurred immersed in distilled water at $37^{\circ} \mathrm{C}$.

The flexural strength (MPa) was calculated based on the formula: $3 \mathrm{PL} / 2 \mathrm{WT}^{2}$, where $\mathrm{P}$ is the load recorded at fracture, $\mathrm{L}$ is distance between supports, $\mathrm{W}$ is specimen width and $\mathrm{T}$ is the specimen thickness [10].

The values obtained for the fracture of the specimens were submitted to descriptive statistical analysis and the parametric one-way analysis of variance (ANOVA) and Tukey test ( $\mathrm{p}$-value $<0.05)$.

\section{Results and discussion}

There were a statistical difference between the groups ( $\mathrm{p}$-value $=0.00$ ). The results are represented at Table 2. The flexural strength of monolithic lithium disilicate is represented by the structure of this material can resist masticatory stress, dissipating it throughout the entire restoration [2]. It was observed a decrease in the mechanical strength of groups submitted to SB neutralization process, with or without ultrasonic cleaning bath. The process of neutralization appears to cause reduction in adhesion between dentin and ceramic, since the reaction between HF and neutralization salt produces sodium fluoride and unstable carbonic acid [4]. These precipitates remain on the ceramic surface, avoiding the penetration of resin materials and hindering the creation of micro-retentions [5]. It could explain the lower flexural strength in the group U. For these precipitates removal, the ultrasonic cleaning bath is one of the mechanisms indicated [5]. The ultrasonic cleaning bath with distillated water increased the bond strength between ceramic and resin cement, because of effective removal of precipitates, since it $\mathrm{F}$ ions are not completely removed only with air-water spray [7].

Table 2 Flexural strength results

\begin{tabular}{ll}
\hline Treatment & Mean \pm standard deviation \\
\hline $\mathrm{C}$ & $256,72 \pm 71,32^{\mathrm{a}}$ \\
\hline $\mathrm{H}$ & $264,80 \pm 33,99^{\mathrm{a}}$ \\
\hline $\mathrm{HC}$ & $317,28 \pm 42,82^{\mathrm{a}}$ \\
\hline $\mathrm{N}$ & $180,86 \pm 63,65^{\mathrm{b}}$ \\
\hline $\mathrm{U}$ & $317,86 \pm 40,86^{\mathrm{a}}$ \\
\hline $\mathrm{NU}$ & $166,09 \pm 43,65^{\mathrm{b}}$ \\
\hline
\end{tabular}

Legend: Mean and standard deviation of flexural strength (MPa). The same superscripted letters indicate no significant differences. 
However, there was no visible improvement in the mechanical properties in this study. So, only air water spray has been sufficient to remove residual ceramic surfaces etched with HF [11]. There is few studies about the effects of neutralization and ultrasonic cleaning bath in bond strength and mechanical properties of lithium disilicate ceramic. The mechanical properties of lithium disilicate ceramic is related to considerable glass percentage in its composition. So, the etching could not weakening its structure to cause strength decrease in the $\mathrm{H}$ group compared to the group $\mathrm{C}$. Additionally, maybe the precipitates formation in this ceramic type was lower when compared with another ceramics, like feldspathic ceramics. So, the neutralization and ultrasonic bath cleaning are unnecessary, because did not increased the flexural strength and results in more clinical steps for the clinicians. For this reason, the neutralization and ultrasonic cleaning bath could be eliminated as surface treatment for a lithium disilicate ceramic in terms of mechanical properties. But, it should be emphasized that bond strength between ceramic and cement could be better after these post-etching protocols.

\section{Conclusion}

The neutralization with supersaturated solution of $\mathrm{SB}$, followed or not by ultrasonic cleaning results in lower mechanical strength of a pressable lithium disilicate ceramic. Etching with 5\% HF did not reduce the flexural strength of this ceramic type.

\section{Abbreviations}

HF: Hydrofluoric acid; SB: Supersaturated solution of sodium bicarbonate.

\section{Competing interests}

The authors declare that they have no competing interests.

\section{Authors' contributions}

TPS prepared and cemented the samples and wrote the paper. CC planned the project and methodology, supervised the literature review and the tests and prepared the final version. LTY did the literature review and performed the strength test. NRR prepared and cement the samples and discussed the study. VCM got the idea, supervised the practical phase and corrected the final version. ETK guided the conception idea, the project planning, the methodology, the statistical analysis, and raised funds to do the study. All authors read and approved the final manuscript.

\section{Acknowledgements}

The authors acknowledge support from Fundação de Amparo à Pesquisa do Estado de São Paulo - FAPESP (2011/11301-6, 2012/12082-9 and 2013/00924-8).

Received: 22 August 2013 Accepted: 1 November 2013

Published: 23 December 2013

References

1. Griggs JA (2007) Recent advances in materials for all-ceramic restorations. Dent Clin North Am 51(3):713-727. viii. doi:10.1016/j.cden.2007.04.006

2. Kang SH, Chang J, Son HH (2013) Flexural strength and microstructure of two lithium disilicate glass ceramics for CAD/CAM restoration in the dental clinic. Restor Dent Endod 38(3):134-140. doi:10.5395/rde.2013.38.3.134

3. Brentel AS, Ozcan M, Valandro LF, Alarca LG, Amaral R, Bottino MA (2007) Microtensile bond strength of a resin cement to feldpathic ceramic after different etching and silanization regimens in dry and aged conditions. Dent Mater 23(11):1323-1331. doi:10.1016/j.dental.2006.11.011

4. Saavedra G, Ariki EK, Federico CD, Galhano G, Zamboni S, Baldissara P, Valandro LF (2009) Effect of acid neutralization and mechanical cycling on the microtensile bond strength of glass-ceramic inlays. Oper Dent 34(2):211-216. doi:10.2341/08-68

5. Canay S, Hersek N, Ertan A (2001) Effect of different acid treatments on a porcelain surface. J Oral Rehabil 28(1):95-101

6. Oh WS, Shen C (2005) Effect of flame cleaning of ceramic surface on the bond strength of composite to ceramic. J Oral Rehabil 32(2):141-144. doi:10.1111/j.1365-2842.2004.01398.x

7. Martins ME, Leite FP, Queiroz JR, Vanderlei AD, Reskalla HN, Ozcan M (2012) Does the ultrasonic cleaning medium affect the adhesion of resin cement to feldspathic ceramic? J Adhes Dent 14(6):507-509. doi:10.3290/j.jad.a28625

8. Standards, International Organization (2008) Dentistry-dental ceramics. Geneva, ISO, 6872 
9. Della Bona A, Anusavice K, Hood JA (2002) Effect of ceramic surface treatment on tensile bond strength to a resin cement. Int J Prosthodont 15(3):248-253

10. Yen TW, Blackman RB, Baez RJ (1993) Effect of acid etching on the flexural strength of a feldspathic porcelain and a castable glass ceramic. J Prosthet Dent 70(3):224-233

11. Belli R, Guimaraes JC, Filho AM, Vieira LC (2010) Post-etching cleaning and resin/ceramic bonding: microtensile bond strength and EDX analysis. J Adhes Dent 12(4):295-303. doi:10.3290/j.jad.a17709

doi:10.1186/2196-4351-1-7

Cite this article as: Sato et al:: Flexural strength of a pressable lithium disilicate ceramic: influence of surface treatments. Applied Adhesion Science 2013 1:7.

Submit your manuscript to a SpringerOpen ${ }^{\odot}$ journal and benefit from:

- Convenient online submission

Rigorous peer review

- Immediate publication on acceptance

- Open access: articles freely available online

- High visibility within the field

Retaining the copyright to your article

Submit your next manuscript at $\boldsymbol{\sim}$ springeropen.com 